Article

\title{
Lignin Accumulation in Three Pumelo Cultivars in Association with Sucrose and Energy Depletion
}

\author{
Juan Liu, Qinghua Huang, Peizi Kang, Lei Liang * and Junjia Chen * \\ Guangdong Key Lab of Sugarcane Improvement \& Biorefinery, Guangdong Provincial Bioengineering \\ Institute (Guangzhou Sugarcane Industry Research Institute), Guangdong Academy of Sciences, \\ Guangzhou 510316, China; ljane0505@126.com (J.L.); qinghuahuang88@126.com (Q.H.); \\ Pansykang@126.com (P.K.) \\ * Correspondence: lianglei214@126.com (L.L.); gzcsircjj@163.com (J.C.)
}

Received: 16 August 2019; Accepted: 31 October 2019; Published: 5 November 2019

\begin{abstract}
Lignification, which occurs in many horticultural fruit and vegetables, brings about undesirable texture and unfavorable consumer preference. However, this problem has rarely been studied. In this work, three pumelo cultivars cvs "Hongroumiyou" (HR), "Bairoumiyou" (BR), and "Huangroumiyou" (HuR) were stored at $25^{\circ} \mathrm{C}$ for 90 days, and juice sacs were sampled to explore the lignin accumulation and its relationship to sucrose and energy depletion were investigated. The results displayed that HuR contained lower sucrose content, lower ATP level, but higher lignin content compared to BR and HR during postharvest storage, indicating that the sequence according to storage resistance on the basis of lignin content is as follows: $\mathrm{HuR}<\mathrm{BR}<\mathrm{HR}$. Furthermore, sucrose degradation attributed to enhanced activities of neutral invertase (NI), soluble acid invertase (S-AI), cell wall-bound invertase (B-AI), and energy deficit on account of declined ATP level, showed significantly negative correlation with lignin accumulation, suggesting that lignin accumulation occurrence could induce sucrose degradation and energy deficit during postharvest storage. Additionally, higher activities of phenylalanine ammonia-lyase (PAL), polyphenol oxidase (PPO), peroxidase (POD) could accelerate lignin synthesis and resulted in lignin accumulation during postharvest pumelo storage.
\end{abstract}

Keywords: pummelo; lignin; ATP; sucrose; neutral invertase; soluble acid invertase; cell wall-bound invertase; phenylalanine ammonia-lyase

\section{Introduction}

Pumelo (Citrus maxima (Burm.) Merr.) is a delicious citrus fruit widely distributed in South of Yangtze River, China and Southeast Asia. However, harvested pumelo fruit are vulnerable to juice sac granulation featured by sacs being more and more stiffened, dried, and flavor-undesirable during storage at ambient temperature. These problems can bring about quality deterioration and economic loss. Previously, it was well-documented that lignin accumulated in postharvest pumelo fruit during juice sac granulation process [1-4]. Moreover, lignin accumulation occurs not only in harvested pumelo fruit, but also in other fruit, for instance, mangosteen, loquat, kiwifruit [5-7]. Not only in normal ripening process, lignin accumulation occurrence has also been observed commonly in postharvest fruit and vegetable under environmental stress [8,9]. Lignin accumulation can result in heavy quality problems and great marketability loss. Therefore, it will be important to reveal the underlying mechanism of lignin accumulation, such as the major factor affecting the lignin accumulation process.

Lignin is a phenolic heteropolymer consisting three monolignols, sinapyl alcohol, coniferyl alcohol, and $p$-coumaryl alcohol which are synthesized via phenylpropanoid pathway $[10,11]$. Several enzymes have been found to play a critical role in lignin synthesis. Among them, PAL is involved more particularly in the cleavage of phenylalanine to cinnamic acid, PPO is mainly responsible for catalyzing 
cumaric acid to caffeic acid and consequently accelerate the lignin synthesis, while POD is considered as an important enzyme in the final step of catalyzing monolignols to be polymerized to lignin [12,13]. Previous studies conducted in citrus fruit indicated that increased lignin content was accompanied by enhanced activities of PAL, PPO, and POD during postharvest storage $[7,13,14]$.

On the one hand, it has been reported that lignin synthesis was related to carbohydrate metabolism via shikimate pathway [15]. Three invertases included NI, S-AI, B-AI are thought to be the key enzymes for catalyzing the cleavage of sucrose into fructose and glucose. Hence, enhanced activities of invertases could be a symbol of increased hexose availability [16]. Previous studies conducted on transgenic tobacco indicated that overexpression of a yeast invertase could induce high accumulation of soluble sugars [17]. On the other hand, energy deficit was found to be closely related to lignin accumulation in postharvest fruit $[18,19]$. Our previous study showed that reduced ATP level and energy charge of harvested banana fruit could accelerate chilling injury incidence [20]. Recently, new evidence on postharvest loquat fruit have demonstrated that energy deficit played a role in lignin accumulation [21].

The purpose of this study was to investigate the differences among three pumelo cultivars during postharvest storage, in addition, lignin accumulation and its relationship to sucrose and energy depletion were also explored. Specific analyses included soluble sugars contents, ATP level, lignin content, invertases (NI, S-AI, B-AI), and enzymes (PAL, PPO, POD) related to lignin synthesis. Probable mechanism of lignin accumulation in juice sacs of pumelo fruit was also proposed.

\section{Materials and Methods}

\subsection{Plant Materials and Treatments}

Three cultivars of pumelo fruit, "Hongroumiyou," "Bairoumiyou," and "Huangroumiyou" abbreviated as HR, BR, and HuR, were harvested at commercial maturity on 1 October 2018 from Dapu county, Meizhou city, Guangdong province. Fifty fruit of each cultivar was packaged with polyethylene film (0.03 mm thick) bags, and stored at $25{ }^{\circ} \mathrm{C}$ and $70 \%-85 \%$ relative humidity. Six fruit from each cultivar were separately taken at $0,15,30,60$, and $90 \mathrm{~d}$, peeled and juice sacs without segment membranes were used as plant materials for analyzing sugar, energy, and lignin.

\subsection{Determination of Sugar}

The analysis and extraction of sugar content was modified from a method put forward by previous reports [22]. Briefly, juice sacs of three cultivars were frozen in liquid nitrogen and ground into powder. A total of $3 \mathrm{~g}$ of powdered sample was weighed and extracted with $3 \mathrm{~mL}$ deionized water by vortexing for $2 \mathrm{~min}$ and followed by ultrasonic extraction at $40^{\circ} \mathrm{C}$ for $1 \mathrm{~h}$. The extract was centrifuged at $12,000 \times$ $g$ for $10 \mathrm{~min}$ and the supernatant was subjected to HPLC analysis. Extracts were analyzed by ALTUS A-10 (Perkin Elmer) consisting of a differential refraction detector, equipped with Durashell amino column $(5 \mu \mathrm{m}, 4.6 \times 250 \mathrm{~mm})$. The column temperature was $40{ }^{\circ} \mathrm{C}$. Injection volume was $20 \mu \mathrm{L}, 70 \%$ acetonitrile and $30 \%$ deionized water were used as mobile phases at a flow rate of $1 \mathrm{~mL} \mathrm{~min}^{-1}$. The sugar concentration was obtained from the sugar standard curve. Sugar contents were expressed as $\mathrm{mg} \mathrm{g}^{-1}$. The contents of sugars were calculated using the following equation:

$$
\text { Sugar contents }=\left(\left(\mathrm{C}-\mathrm{C}_{0}\right) \times \mathrm{V} \times \mathrm{n}\right) /(\mathrm{m} \times 1000) \times 100
$$

where $C$ is the sugar concentration obtained from the sugar standard curve, $C_{0}$ is the sugar concentration of blank control, and $\mathrm{n}$ is the dilution ratio. $\mathrm{V}$ is the volume and $\mathrm{m}$ is the weight of samples. Total soluble sugar was determined according to previously reported methods [23].

\subsection{Assays of Enzyme Activities}

Five grams of powdered juice sacs from three cultivars of pumelo were used for measuring NI, S-AI, and B-AI activities. For measuring NI activity, five grams of powdered juice sacs were extracted 
with $50 \mathrm{~mL}$ sodium phosphate solution ( $\mathrm{pH} 7.8$ ) and centrifuged at $12,000 \times g$ for $10 \mathrm{~min}$ at $4{ }^{\circ} \mathrm{C}$. Total of $40 \mu \mathrm{L}$ of the supernatant was mixed with $200 \mu \mathrm{L} 0.1 \mathrm{~mol} \mathrm{~L}^{-1}$ sucrose solution (PBS (pH7.5) for the control) and heated at $37^{\circ} \mathrm{C}$ for $20 \mathrm{~min}$, followed by another heating at $95^{\circ} \mathrm{C}$ for $10 \mathrm{~min}$. The mixture was cooled down by flowing water and added with $100 \mu \mathrm{L}$ DNS. The reaction was performed at $95^{\circ} \mathrm{C}$ for $10 \mathrm{~min}$, and the absorbance was measured at $540 \mathrm{~nm}$. For measuring S-AI activity, the reagents and analysis procedure were the same as the NI activity except that the control was added with $200 \mu \mathrm{L}$ $0.1 \mathrm{~mol} \mathrm{~L}^{-1} \mathrm{HAC}-\mathrm{NaAC}$ ( $\mathrm{pH}$ 4.8). For measuring B-AI activity, five grams of powdered juice sacs were extracted with $50 \mathrm{~mL}$ sodium phosphate solution $(\mathrm{pH} 7.8)$ and centrifuged at $12,000 \times g$ for $10 \mathrm{~min}$ at $4{ }^{\circ} \mathrm{C}$, and the sediment was retained and added with $50 \mathrm{~mL}$ distilled water and centrifuged at $12,000 \times g$ for $10 \mathrm{~min}$ at $4{ }^{\circ} \mathrm{C}$, and the sediment retained was mixed with $50 \mathrm{~mL} 0.5 \mathrm{~mol} \mathrm{~L}{ }^{-1} \mathrm{NaCl}$ solution at $4{ }^{\circ} \mathrm{C}$ overnight, and centrifuged at $12,000 \times \mathrm{g}$ for $20 \mathrm{~min}$ at $4{ }^{\circ} \mathrm{C}$. The supernatant was mixed with $200 \mu \mathrm{L} 0.1 \mathrm{~mol} \mathrm{~L}^{-1}$ sucrose solution $\left(0.1 \mathrm{~mol} \mathrm{~L}{ }^{-1}\right.$ HAC-NaAC ( $\left.\mathrm{pH} 4.8\right)$ for the control) and heated at $37^{\circ} \mathrm{C}$ for $20 \mathrm{~min}$, followed by another heating at $95^{\circ} \mathrm{C}$ for $10 \mathrm{~min}$. The mixture was cooled down by flowing water and added with $100 \mu \mathrm{L}$ DNS. The reaction was performed at $95{ }^{\circ} \mathrm{C}$ for $10 \mathrm{~min}$, and the absorbance was measured at $540 \mathrm{~nm}$. $\mathrm{U} \mathrm{g}^{-1}$ protein was used to express the enzyme activity.

\subsection{Determination of $A T P, A D P$, and $A M P$}

Two grams of juice sacs from three cultivars of pumelo were used for measuring ATP, ADP, and AMP according to our previously reported methods [20]. $\mathrm{gg} \mathrm{g}^{-1}$ fresh weight was used to express the level of ATP, ADP, and AMP.

\subsection{Assays of PAL, POD, and PPO Activities}

PAL activity was measured by a method described by Jiang and Joyce [24]. For determining POD activity, four grams of fruit juice sacs was homogenized under liquid nitrogen and $20 \mathrm{~mL} 0.2 \mathrm{~mol} \mathrm{~L}^{-1}$ phosphate buffer ( $\mathrm{pH}$ 6.8) was added to it which contained $100 \mu \mathrm{mol} \mathrm{L}{ }^{-1}$ EDTA, then $0.4 \mathrm{~g}$ PVP was added and grinded in an ice bath. After centrifugation at $15,000 \times g$ for $15 \mathrm{~min}$ at $4{ }^{\circ} \mathrm{C}$ and the supernatant was taken to measure the enzyme activity. A total of $0.05 \mathrm{~mL}$ of the supernatant was taken and added to a reaction solution containing $0.1 \mathrm{~mL} 4.0 \%$ guaiacol, $0.1 \mathrm{~mL} 0.46 \%$ hydrogen peroxide, and $2.75 \mathrm{~mL}$ phosphate buffer, the absorbance was measured at $470 \mathrm{~nm}$ and one unit (U) of POD was defined as 0.01 of absorbance fluctuation per minute. PPO activity was measured according to previous study [25].

\subsection{Measurement of Lignin}

A total of $1 \mathrm{~g}$ of powdered juice sacs from three cultivars of pumelo fruit were extracted with $20 \mathrm{~mL} 80 \%$ ethanol by vortexing for $2 \mathrm{~min}$, followed by treatment in water bath at $95{ }^{\circ} \mathrm{C}$ for $10 \mathrm{~min}$. The extract was cooled down by flowing water and centrifuged at $8000 \mathrm{rpm}$ for $10 \mathrm{~min}$. The sediment was kept and added with $15 \mathrm{~mL} 80 \%$ ethanol by vortexing for $2 \mathrm{~min}$, followed by treatment in water bath at $95{ }^{\circ} \mathrm{C}$ for $10 \mathrm{~min}$. After $10 \mathrm{~min}$ centrifugation at $8000 \mathrm{rpm}$, the sediment was obtained and extracted with $10 \mathrm{~mL}$ DMSO for $15 \mathrm{~h}$. The extract was centrifuged at $8000 \mathrm{rpm}$ for $10 \mathrm{~min}$ and the sediment was extracted with $10 \mathrm{~mL}$ acetone, followed by centrifugation at $8000 \mathrm{rpm}$ for $10 \mathrm{~min}$. The procedure of extraction with acetone and centrifugation was repeated three times. The sediment was lyophilized. Fifteen milligram sediment sample was weighed and mixed with $1 \mathrm{~mL}$ acetyl bromide, followed by treatment in water bath at $50{ }^{\circ} \mathrm{C}$ for $2 \mathrm{~h}$ with shaking every $15 \mathrm{~min}$. The mixture was homogenized with $4 \mathrm{~mL} \mathrm{NaOH}$ and $700 \mu \mathrm{L}$ hydroxylamine hydrochloride, then diluted with $80 \%$ acetic acid to $10 \mathrm{~mL}$. Absorbance was measured using a UV-Vis spectrophotometer at $280 \mathrm{~nm} . \mathrm{mg} \mathrm{g}^{-1}$ was used to express the lignin content.

\subsection{Statistical Analysis}

All parameters were analyzed three times. The values in figures and table were represented in form of the mean \pm SE (standard error) $(n=3)$. Data was processed using the software SPSS statistics 
22.0, and the results of cultivar BR were used for the correlation analysis in this study. Significant difference were examined by one-way analysis of variance. The value of $p<0.01$ or $p<0.05$ represented very significant difference or significant difference, respectively.

\section{Results}

\subsection{Changes in Sugar Content in Juice Sacs of Three Pummelo Cultivars}

Figure 1 showed that at harvest, BR and HuR contained high content of total soluble sugar, which reduced after $30 \mathrm{~d}$ of storage, increased after $60 \mathrm{~d}$ of storage and decreased after $90 \mathrm{~d}$ of storage. Total soluble sugar content of HR showed tendency of continuous enhancement until $60 \mathrm{~d}$ of storage, thereafter, decreased slightly (Figure 1A). Accordingly, fructose and glucose contents increased to maximum at $30 \mathrm{~d}$ of storage (exception, glucose of $\mathrm{HR}$ at $60 \mathrm{~d}$ ), subsequently declined with the extension of storage (Figure 1B,D). Similarly, a rise from $0 \mathrm{~d}$ to $30 \mathrm{~d}$ followed by a decline from $30 \mathrm{~d}$ to $90 \mathrm{~d}$ were observed in sucrose contents of HR (Figure 1C). Unlike them, sucrose contents of BR and HuR decreased slightly during postharvest storage (Figure 1C). Compared to BR and HR, HuR contained significantly lower sucrose content during the whole storage time. The sucrose content continuously declined in juice sacs of HuR and BR during the whole storage time, while that of HR increased to a peak at $30 \mathrm{~d}$ and then decreased as the storage time extended. From $30 \mathrm{~d}$ to $60 \mathrm{~d}$ of storage, the sucrose content in HR was the highest, followed by BR and HuR was the lowest.

These data highlighted that faster sucrose depletion, which resulted in lower sucrose content, could be observed in juice sacs of $\mathrm{HuR}$ in contrast to the other two cultivars during postharvest storage.
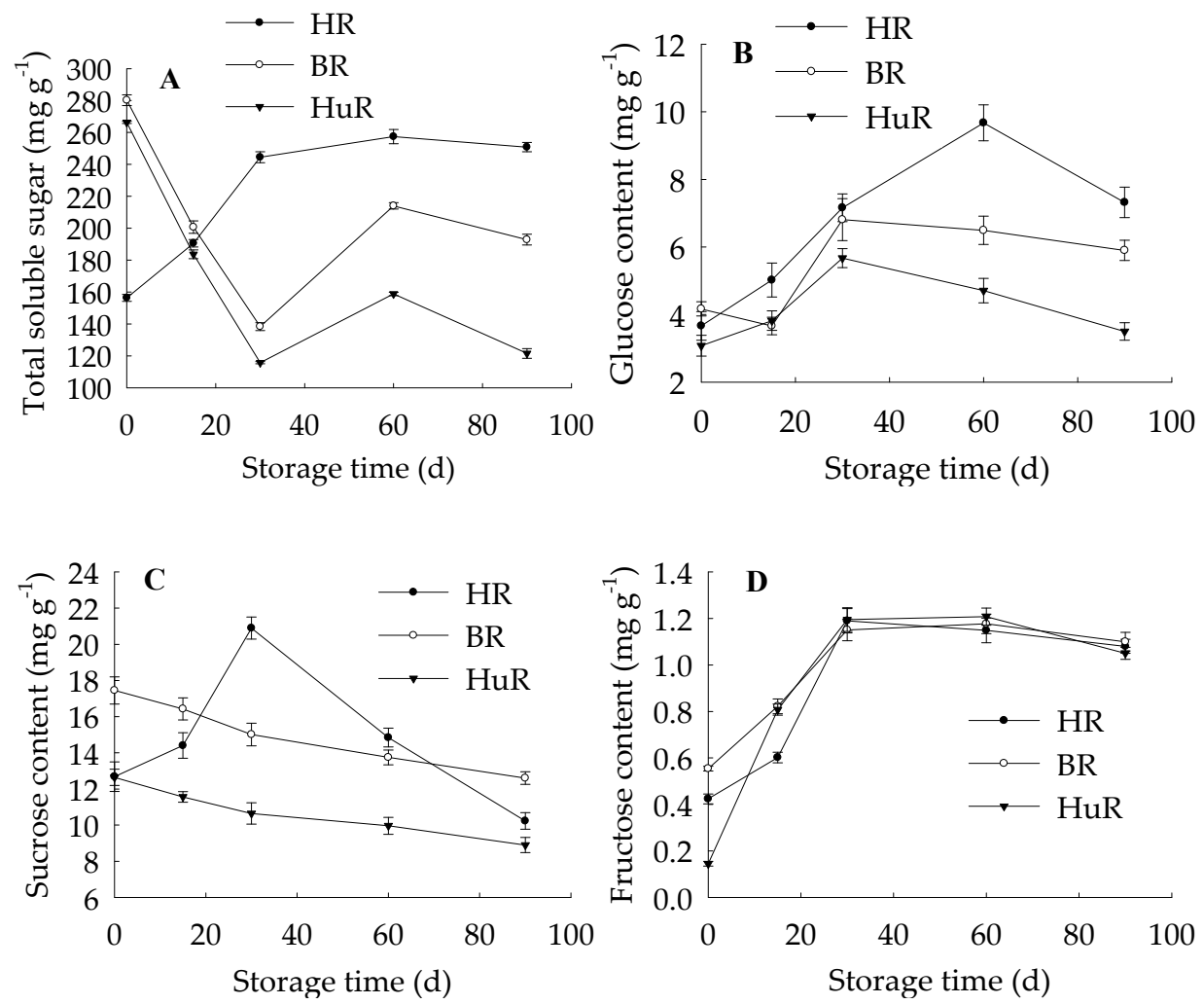

Figure 1. Changes in contents of total soluble sugar (A), glucose (B), sucrose (C), and fructose (D) in juice sacs of three pumelo cultivars. Vertical bars represent SE of the means of three replicate assays.

\subsection{Changes in NI, S-AI, B-AI Activities in Juice Sacs of Three Pummelo Cultivars}

As shown in Figure 2, NI (Figure 2A), S-AI (Figure 2B), and B-AI (Figure 2C) activities showed a rising trend in pumelo juice sacs of three cultivars during postharvest storage. Compared to HuR ang 
$\mathrm{BR}$, the activities of NI, S-AI and B-AI in juice sacs of $\mathrm{HR}$ were lower from $0 \mathrm{~d}$ to $30 \mathrm{~d}$ of storage. In addition, HuR showed higher B-AI activity than BR and HR from $0 \mathrm{~d}$ to $30 \mathrm{~d}$ of storage. At $30 \mathrm{~d}$ of storage, HuR displayed the highest NI, S-AI, and B-AI activities, followed by BR and then HR. As storage time proceeded, the activities of NI, S-AI, and B-AI increased in juice sacs of three pumelo cultivars, and BR was the highest, followed by HR and then HuR from $60 \mathrm{~d}$ to $90 \mathrm{~d}$ of storage.
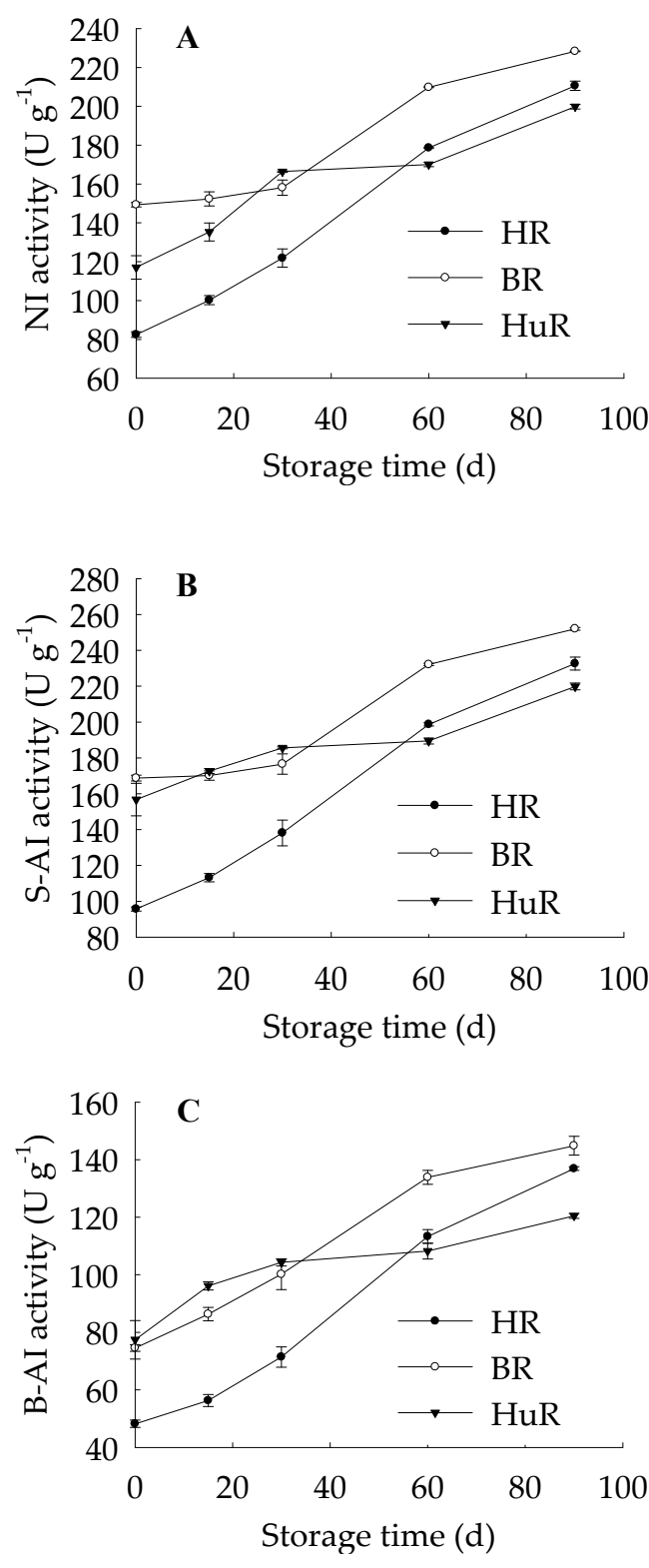

Figure 2. Changes in NI (A), S-AI (B), B-AI(C) activities in juice sacs of three pumelo cultivars. Vertical bars represent SE of the means of three replicate assays. NI, neutral invertase; S-AI, soluble acid invertase; B-AI, cell wall insoluble acid invertase.

These data revealed that the NI, S-AI, and B-AI activities of juice sacs of three pumelo cultivars were observed to increase as the storage time proceeded, which was suggested to contribute to sucrose degradation. Higher activities of NI, S-AI, and B-AI in juice sacs of HuR at $30 \mathrm{~d}$ of storage could result in lower sucrose content during the postharvest storage. 


\subsection{Changes in ATP, ADP, and AMP Levels in Juice Sacs of Three PUMMELO Cultivars}

Figure 3 showed that at harvest pumelo fruit reserved high levels of ATP (Figure 3A) and ADP (Figure 3B), but relatively low AMP content (Figure 3C). As the storage time extended, ATP and ADP levels decreased, but AMP level increased. Furthermore, ADP and AMP levels decreased from $15 \mathrm{~d}$ to $60 \mathrm{~d}$, thereafter, ADP level exhibited a sharp increase from $60 \mathrm{~d}$ to $90 \mathrm{~d}$, while AMP level declined slowly. In particular, ATP level decreased during the whole storage. Compared to the other two cultivars, HuR contained lower level of ATP from $15 \mathrm{~d}$ to the rest of storage time, suggesting that cellular energy deficit in juice sacs of $\mathrm{HuR}$ was the most obvious in contrast to BR and HR.
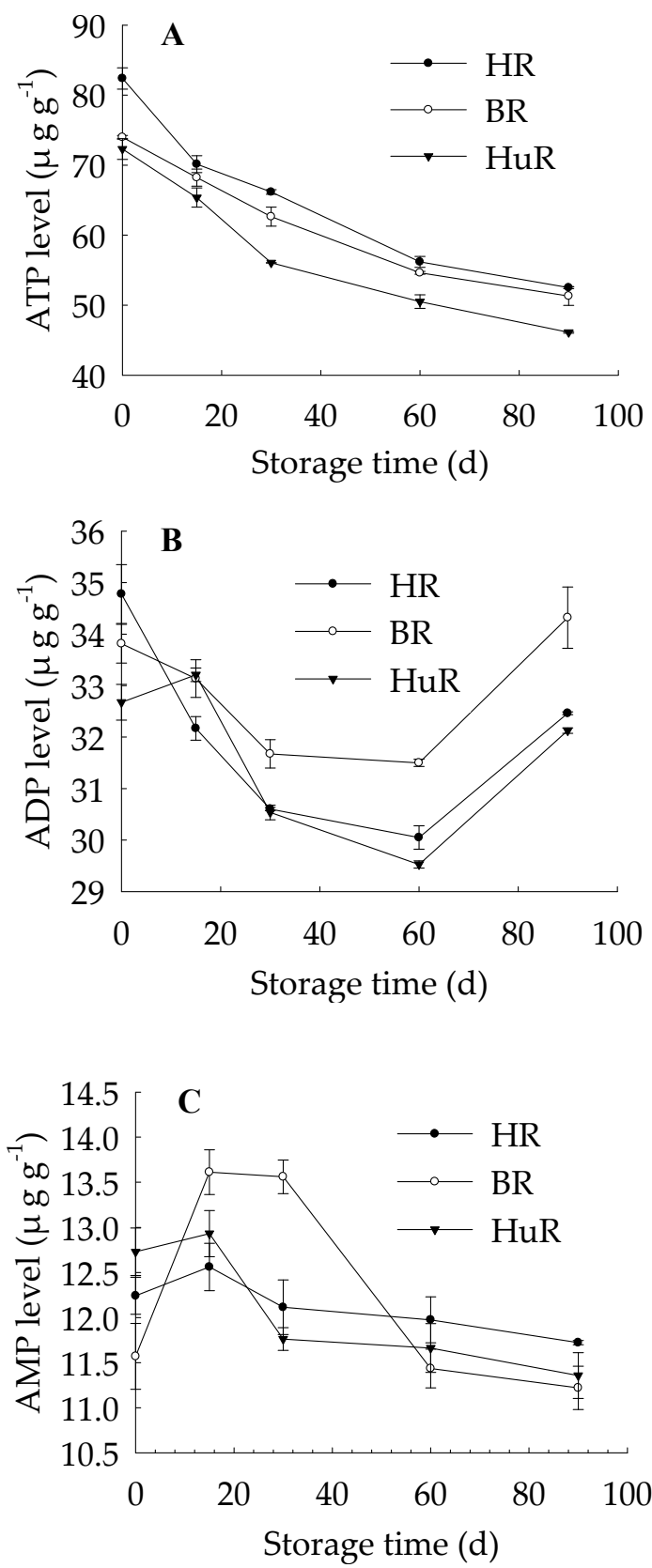

Figure 3. Changes in ATP (A), ADP (B), AMP (C) levels in juice sacs of three pumelo cultivars. Vertical bars represent $\mathrm{SE}$ of the means of three replicate assays.

These data implied that energy deficit, which was featured by declined ATP level, was one typical physiological change in juice sacs of three pumelo cultivars during postharvest storage. Cultivar of 
HuR maintained the lowest ATP level from $15 \mathrm{~d}$ to $90 \mathrm{~d}$, followed by BR and HR during postharvest storage time.

\subsection{Changes in Lignin Content in Juice Sacs of Three Pummelo Cultivars}

Figure 4 illustrated that juice sacs lignin content elevated gradually before the $15 \mathrm{~d}$ of storage, thereafter, a sharp increase was displayed in BR and HuR from $15 \mathrm{~d}$ to $60 \mathrm{~d}$ of storage, then followed by gradual enhancement during the remaining storage. Meanwhile, juice sacs lignin content of HR exhibited relatively slower increase before $60 \mathrm{~d}$ of storage, but sharp increase from $60 \mathrm{~d}$ to $90 \mathrm{~d}$ of storage. Compared to HR, the lignin accumulation was higher in $\mathrm{HuR}$ and BR, indicating that lignin accumulation occurrence of pumelo fruit from easier to harder was HuR, BR, and HR.

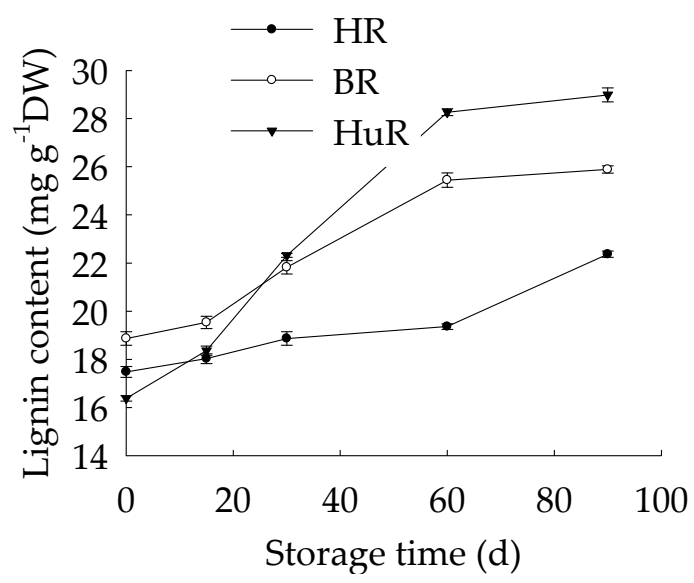

Figure 4. Changes in lignin content in juice sacs of three pumelo cultivars. Vertical bars represent SE of the means of three replicate assays. DW, dry weight.

These data indicated that lignin content increased as the storage time extended in juice sacs of three pumelo cultivars, and this would result in juice sacs granulation of pumelo fruit and consequently lead to loss of nutrition and commodity value. Cultivar of HuR is more vulnerable to lignin accumulation, followed by BR and then HR during postharvest storage, indicating that the storage resistance of $\mathrm{HuR}$ was less than BR and HR.

\subsection{Changes in PAL, PPO, and POD Activities in Juice Sacs of Three Pummelo Cultivars}

Figure 5 also displayed that PAL activity (Figure 5A) in pumelo fruit increased from $0 \mathrm{~d}$ to $60 \mathrm{~d}$ of storage, thereafter, decreased during the following storage. Meanwhile, PAL activity in HR was much higher than in HuR and BR during the whole storage. As to PPO activity (Figure 5B), which increased more drastically in HuR than HR and BR between $15 \mathrm{~d}$ and $60 \mathrm{~d}$ of storage, showed sharp decline after $60 \mathrm{~d}$ of storage. Moreover, juice sacs POD activity (Figure 5C) exhibited a gradual rise until $30 \mathrm{~d}$, followed by a sharp increase from $30 \mathrm{~d}$ to $60 \mathrm{~d}$ in BR and HR and a slight rise in HuR, and then a sharp decline was displayed from $60 \mathrm{~d}$ to $90 \mathrm{~d}$ in three cultivars. It was worthy to be noticed that the PPO activity from $15 \mathrm{~d}$ to $60 \mathrm{~d}$ of storage was higher in the order of HuR, BR, and HR, and the same order was observed in POD activity from $0 \mathrm{~d}$ to $30 \mathrm{~d}$.

These data indicated that increased PAL, PPO, and POD activities could contribute to lignin accumulation in juice sacs of three pumelo cultivars during postharvest storage. In addition, compared to BR and HR, higher PPO activity from $15 \mathrm{~d}$ to $60 \mathrm{~d}$ and higher POD activity from $0 \mathrm{~d}$ to $30 \mathrm{~d}$ might result in higher lignin content in juice sacs of HuR. 

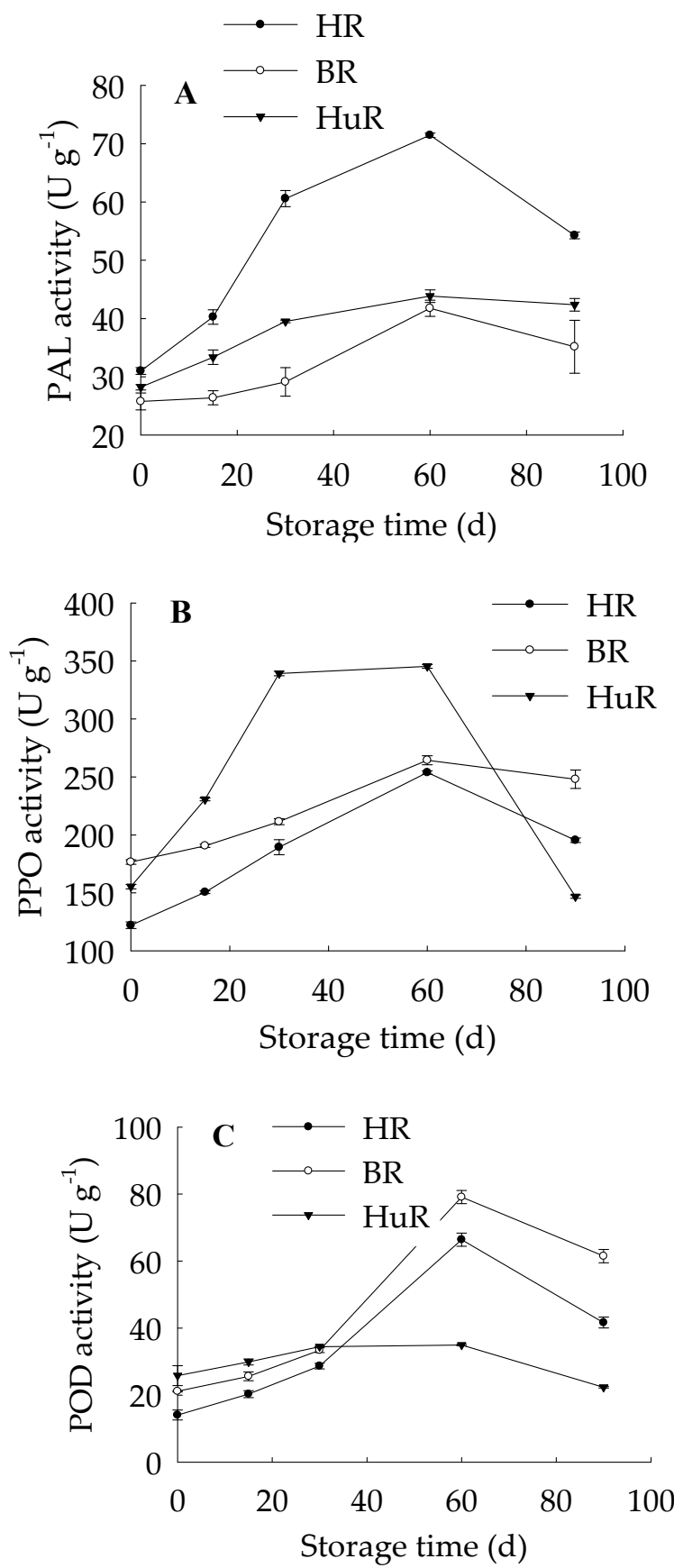

Figure 5. Changes in PAL (A), PPO (B), POD (C) activities in juice sacs of three pumelo cultivars. Vertical bars represent $\mathrm{SE}$ of the means of three replicate assays.

\section{Discussion}

\subsection{Lignin Accumulation Was Correlated with Sugar Metabolism}

Based on previous documents, sucrose acted as the core of respiration metabolism and provided precursor for various substances synthesis; therefore, lignin synthesis was closely related to sucrose content in plants. Specifically, phenylpropanoid pathway, which produces monolignols of lignin, is connected with sugar metabolism through shikimate pathway in which phenylalanine is produced [15]. It was shown that, lignin accumulated when sugar was in rapid decrease in the peach endocarp, indicating that lignin accumulation was in association with the declined sugar content, which accelerated the pit hardening process [26]. Other studies showed that total soluble sugar content 
increased significantly as well as lignin, and genes related to glucose and lignin synthesis were strongly induced by boron deficiency stress in leaves of citrus [27]. The possible link between lignin accumulation with sugar metabolism was reinforced by the observation that sugars availability positively affected the cell wall biosynthesis, which included lignin synthesis in Arabidopsis thaliana [28].

In the present study, the linearity regression analysis indicated that the increased lignin content in harvested pumelo fruit showed a significantly positive relation ( $\mathrm{r}=0.93, p<0.05)$ (Table S1) with total soluble sugar from $0 \mathrm{~d}$ to $30 \mathrm{~d}$. Furthermore, the decrease in sucrose content showed a significantly negative relation with the increased lignin content $(r=-0.976, p<0.05)$ (Table S1). Moreover, the lowest sucrose content in juice sacs of $\mathrm{HuR}$ and the highest lignin content from $30 \mathrm{~d}$ together with the higher sucrose content in juice sacs of HR from $30 \mathrm{~d}$ to $60 \mathrm{~d}$ and the lowest lignin content from 15 $\mathrm{d}$ verified that there was some close relationship between sucrose content and lignin accumulation, directly or indirectly. In addition, the lignin content exhibited a positive relation with glucose $(\mathrm{r}=0.878$, $p<0.05)$ (Table S1) and fructose $(\mathrm{r}=0.822, p<0.05)$ (Table S1). All these data highlighted that low sucrose content and high fructose and glucose contents were beneficial to lignin accumulation in postharvest pumelo fruit. It was worthy to be noticed that the sucrose of HR increased from $0 \mathrm{~d}$ to $30 \mathrm{~d}$ first, and then declined subsequently; however, the fructose and glucose contents increased during the whole storage (Figure 1C), therefore, the lignin accumulation was not influenced for the sake of enough carbon supply.

In our previous study, we found that higher soluble sugar content was beneficial in alleviating chilling injury of postharvest banana fruit during cold storage [20]. This suggests that soluble sugars played an unexpected role in not only normal ripening development but also in cold storage of postharvest fruit. In this work, during the normal ripening development of postharvest pumelo fruit, except for sucrose contents of HR, sucrose content decreased while glucose and fructose contents increased first and then declined slightly in juice sacs of pumelo fruit (Figure 1B-D). In addition, the activities of NI, S-AI, and B-AI kept increasing in three cultivars during the whole storage time. Moreover, the linearity regression analysis revealed that the decreased sucrose content displayed a significantly positive relation with enhanced activities of NI ( $\mathrm{r}=-0.93, p<0.05)$ (Table S2), S-AI $(\mathrm{r}=-0.925, p<0.05)$ (Table S2), and B-AI $(\mathrm{r}=-0.984, p<0.01)$ (Table S2). Invertase plays a direct role in catalyzing irreversible degradation of sucrose to fructose and glucose. It was further reported that the invertase pathway to degrade sucrose was the main route to offer carbon supply to cell wall formation in Arabidopsis cell cultures [29]. Data above highlighted that the decrease in sucrose content could be attributed to the increased NI, S-AI, and B-AI activities, which might accelerate the sucrose degradation and further promote an increase in glucose and fructose contents.

Many studies proposed that lignin accumulation occurs in some other fruits, such as kiwifruit [7], pear [30], asparagus [31], mangosteen [6], loquat [8], wax apple [14], strawberry [32]. Lignin accumulation could be greatly influenced by phenolics biosynthetic pathway and cell wall metabolism during ripening stage of postharvest fruit, indicating that increased lignin content correlated with anthocyanins, flavonoids, and phenylpropanoids as well as polysaccharide and cellulose [31,33]. It has been reported that treatment of nitric oxide, methyl jasmonate, and methyl salicylate significantly inhibited the lignin deposition by enhancing PAL and POD activities in postharvest kiwifruit and wax apple fruit $[7,14]$. Meanwhile conversely, 1-methylcyclopropene aggravated lignin accumulation via inducing a decline in POD activity and other enzymes related to lignin synthesis [7]. PAL is a key rate-limiting enzyme responsible for catalyzation of phenylalanine to cinnamic acid, and POD mainly participates in polymerization of lignin monomer [12]. PPO could provide precursor of lignin synthesis via participating in phenols oxidation [13]. Therefore, to investigate whether the role of PAL, POD, and PPO activities are related to lignin contents, we measured the activities of PAL, POD, and PPO in juice sacs of postharvest pumelo of three cultivars (Figure 5). In addition, the linearity regression analysis of lignin content and PAL, POD, and PPO activities indicated that, the increased lignin content of harvested pumelo fruit showed a significant positive relation with PAL activity $(\mathrm{r}=0.911, p<0.05)$ (Table S1), and a very significantly positive correlation with PPO ( $\mathrm{r}=0.977, p<0.01)$ (Table S1) and 
POD $(r=0.942, p<0.01)$ (Table S1). These results demonstrated the aggravated incidence of lignin accumulation was associated with the enhanced activities of PAL, POD, and PPO in postharvest pumelo fruit.

Taken collectively, lignin accumulation occurrence in juice sacs of BR was positively correlated with sucrose degradation, which could be attributed to increased activities of NI, S-AI, and B-AI activities. Furthermore, enhanced activities of PAL, POD, and PPO contributed to lignin synthesis and gave rise to the occurrence of lignin accumulation in juice sacs of BR. Whether the differences of the above parameters among three pumelo cultivars were statistically significant or not made no difference in the same conclusion in the other two cultivars.

\subsection{Lignin Accumulation Was Correlated with Energy Metabolism}

Sugar metabolism was not the only factor that exerted an important influence on lignin accumulation in postharvest pumelo fruit. There is also considerable evidence of a role for energy metabolism in regulating lignin accumulation. Energy plays a vital role in maintaining normal physiological activities of all living organisms. Insufficient cellular energy supply may result in metabolic disorder of harvested horticultural fruit, such as peel browning in lichi and longan [34,35], pits on blue berry [36], chilling injury of papaya and banana [20,37]. Early studies in loquat fruit indicated that energy deficit was connected closely with lignification at low temperature storage [18]. It was also previously shown that reduced lignification was involved more particularly in energy status maintenance and enhanced antioxidant enzymes activities of water bamboo shoot [32]. Moreover, It has also been reported that ATP level displayed a reverse correlation with lignification, which could be inhibited by low activities of PAL and POD, whereas, application of exogenous ATP was beneficial to protect the postharvest white mushroom against the development of lignification [19]. It was also recently shown that the relative transcriptions of genes related to lignin synthesis were effectively down-regulated, in the meantime, high energy status was maintained by an exogenous peptide treatment on postharvest loquat fruit at $0{ }^{\circ} \mathrm{C}$ [21]. In our previous study, we found that a delay in ATP decline and maintenance of high energy status was beneficial in alleviating chilling injury symptoms in postharvest banana fruit [20]. Furthermore, many studies investigated that high ATP level could protect postharvest fruit against pericarp darkening or browning incidence [21,38].

In the present work, energy deficit featured by declined ATP level became more and more obvious in postharvest pumelo fruit during postharvest storage (Figure $3 \mathrm{~A}$ ). Accordingly, the linearity regression analysis implied that lignin content displayed a very significant reverse relation with ATP $(r=-0.987, p<0.01)$ (Table S1). This gave strong credence for a participation of ATP in lignin synthesis process probably as indicator of cell energy homeostasis in relation to metabolic activity. Moreover, results above might attributed to energy required to carry on various metabolic pathway such as the lignin accumulation process, therefore, the accumulated lignin amounts were observed at the price of continuous ATP depletion in postharvest pumelo fruit. In this meaning, it would be further speculated that exogenous treatments which are beneficial to maintain energy status might delay lignin accumulation in postharvest pumelo fruit, which is in agreement with reduced lignin accumulation under high $\mathrm{O}_{2} / \mathrm{CO}_{2}$ controlled atmosphere or low temperature storage as reported by previous studies $[19,38]$. Meanwhile conversely, those exogenous applications which accelerate energy depletion might contribute to lignin accumulation in postharvest pumelo fruit, which was in accordance with the results of our present work, because the pumelo fruit was stored at room temperature at which fruit respiration rate was high, therefore fast energy consumption could accelerate lignin accumulation.

The above results indicated that the continuously declining ATP levels can result in cellular energy deficit in juice sacs of pumelo fruit, and consequently accelerate the lignin accumulation and senescence directly or indirectly of harvested pumelo fruit.

In summary, the sucrose degradation together with ATP depletion contribute to the lignin accumulation during postharvest pumelo storage. The possible mechanism of lignin accumulation of postharvest pumelo fruit by relying on sugar and energy depletion is shown in Figure 6. 


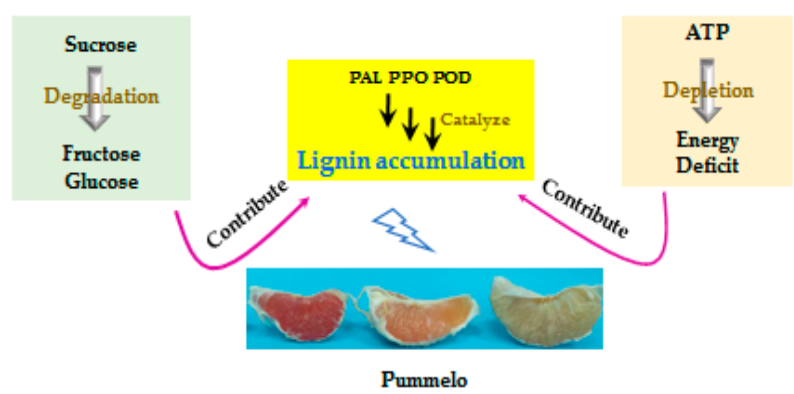

Figure 6. Probable mechanism of lignin accumulation in juice sacs of three pumelo cultivars by acting on the metabolism of sugar and energy.

\section{Conclusions}

In this study, we compared soluble sugars contents, ATP level, lignin content, invertases (NI, S-AI, $\mathrm{B}-\mathrm{AI})$ related to sucrose depletion and enzymes (PAL, PPO, POD) related to lignin synthesis in juice sacs of HuR, BR, and HR. Compared to BR and HR, HuR contained lower sucrose content, lower ATP level, and higher lignin content. The storage resistance of HR was better than BR and HuR on account of lignin content. In addition, we revealed the aggravated lignin accumulation in juice sacs of BR was negatively correlated with the sucrose degradation which was attributed to enhanced activities of NI, S-AI and B-AI, and the energy deficit which was due to declined ATP level. Moreover, enhanced activities of PAL, PPO, and POD can accelerate the lignin accumulation in postharvest pumelo fruit.

Supplementary Materials: The following are available online at http://www.mdpi.com/2218-273X/9/11/701/s1, Table S1: Correlation between ATP, sugars, and related enzymes with lignin in pericarp of BR. Table S2: Correlation between invertases with sucrose in pericarp of BR.

Author Contributions: Conceptualization, J.L.; methodology, Q.H., P.K., L.L., and J.C.; Writing-Original Draft preparation, J.L.

Funding: This research was funded by GDAS' Project of Science and Technology Development (2019GDASYL-0302005 and 2019GDASYL-0103037), and National Natural Science Foundation of China (31901748).

Acknowledgments: We thank South China Botanical Garden for their assistance in sample collection and experimental platform.

Conflicts of Interest: The authors declare no conflict of interest.

\section{References}

1. Pan, D.M.; Zheng, G.H.; Chen, G.X.; She, W.Q.; Guo, Z.X.; Shi, M.T.; Lin, H.Y. Analysis of the reasons caused granulation of juice sacs in Guanximiyou pomelo variety. J. Fruit Sci. 1999, 16, 202-209.

2. She, W.Q. An Analysis on Physiological Changes and Gene Differential Expressions in the Process of Pummelo Fruit [Citrus grandis (L.) osbeck] Juice sac Granulation. Ph.D. Thesis, Fujian Agriculture and Forestry University, Fuzhou, China, 2009.

3. Shomer, I.; Chalutz, E.; Vasiliver, R.; Lomaniec, E.; Berman, M. Scierification of juice sacs in pummelo (Citrus grandis) fruit. Can. J. Bot. 1989, 67, 625-632. [CrossRef]

4. Wu, J.L.; Pan, T.F.; Guo, Z.X.; Pan, D.M. Specific lignin accumulation in granulated juice sacs of citrus maxima. J. Agric. Food Chem. 2014, 62, 12082-12089. [CrossRef] [PubMed]

5. Jing, Z.; Hang, G.; Chen, Z.; Xian, L.; Donald, G.; Chen, K.S.; Yin, X.R. Ejodo1, a MYB transcription factor, regulating lignin biosynthesis in developing loquat (Eriobotrya japonica) fruit. Front. Plant. Sci. 2016, 7, 1360.

6. Kamdee, C.; Imsabai, W.; Kirk, R.; Allan, A.C.; Ferguson, I.B.; Ketsa, S. Regulation of lignin biosynthesis in fruit pericarp hardening of mangosteen (Garcinia mangostana L.) after impact. Postharvest Biol. Technol. 2014, 97, 68-76. [CrossRef]

7. Li, H.; Suo, J.; Han, Y.; Liang, C.; Jin, M.; Zhang, Z.; Rao, J. The effect of 1-methylcyclopropene, methyl jasmonate and methyl salicylate on lignin accumulation and gene expression in postharvest 'xuxiang' kiwifruit during cold storage. Postharvest Biol. Technol. 2017, 124, 107-118. [CrossRef] 
8. Cai, C.; Xu, C.J.; Li, X.; Ferguson, I.; Chen, K.S. Accumulation of lignin in relation to change in activities of lignification enzymes in loquat fruit flesh after harvest. Postharvest Biol. Technol. 2006, 40, 163-169. [CrossRef]

9. Ranadive, A.S.; Haard, N.F. Peroxidase localization and lignin formation in developing pear fruit. J. Fruit Sci. 2010, 37, 381-383. [CrossRef]

10. Boudet, A.M.; Kajita, S.; Grima-Pettenati, J.; Goffner, D. Lignins and lignocellulosics: A better control of synthesis for new and improved uses. Trends Plant Sci. 2003, 8, 576-581. [CrossRef]

11. Donaldson, L.A. Lignification and lignin topochemistry-An ultrastructural view. Phytochemistry 2001, 57, 859-873. [CrossRef]

12. Ipelcl, Z.; Ogras, T.; Altinkut, A. Reduced leaf peroxidase activity is associated with reduced lignin content in transgenic poplar. Plant Biotechnol. 1999, 16,381-387.

13. Sabella, E.; Luvisi, A.; Aprile, A.; Negro, C.; Vergine, M.; Nicolì, F.; Miceli, A.; Bellis, L.D. Xylella fastidiosa induces differential expression of lignification related-genes and lignin accumulation in tolerant olive trees cv. leccino. J. Plant Physiol. 2018, 220, 60-68. [CrossRef] [PubMed]

14. Hao, Y.; Chen, F.; Wu, G.; Gao, W. Impact of postharvest nitric oxide treatment on lignin biosynthesis-related genes in wax apple (Syzygium samarangense) fruit. J. Agric. Food Chem. 2016, 64, 8483-8490. [CrossRef]

15. Herrmann, K.M.; Weaver, L.M. The shikimate pathway. Annu. Rev. Plant Phys. 1999, 50, 473-503. [CrossRef] [PubMed]

16. Kocal, N.; Sonnewald, U.; Sonnewald, S. Cell wall-bound invertase limits sucrose export and is involved in symptom development and inhibition of photosynthesis during compatible interaction between tomato and Xanthomonas camtpestris pv vesicatoria. Plant Physiol. 2016, 148, 1523-1536. [CrossRef]

17. Schaewen, A.V.; Stitt, M.; Schmidt, R.; Sonnewald, U.; Willmitzer, L. Expression of a yeast-derived invertase in the cell wall of tobacco and Arabidopsis plants leads to accumulation of carbohydrate and inhibition of photosynthesis and strongly influences growth and phenotype of transgenic tobacco plants. EMBO J. 1990, 9, 3033-3044. [CrossRef]

18. Chen, F.; Zhang, M.; Wu, G. Study of lignification's delaying and its relationship with energy metabolism in loquat fruits after nitric oxide fumigation. Sci. Agric. Sin. 2014, 47, 2425-2434.

19. Li, L.; Kitazawa, H.; Wang, X.; Sun, H. Regulation of respiratory pathway and electron transport chain in relation to senescence of postharvest white mushroom (Agaricus bisporus) under high $\mathrm{O}_{2} / \mathrm{CO}_{2}$ controlled atmospheres. J. Agric. Food Chem. 2017, 65, 3351-3359. [CrossRef]

20. Liu, J.; Li, F.J.; Li, T.T.; Yun, Z.; Duan, X.W.; Jiang, Y.M. Fibroin treatment inhibits chilling injury of banana fruit via energy regulation. Sci. Hortic. 2019, 248, 8-13. [CrossRef]

21. Song, H.; Wang, X.; Hu, W.; Yang, X.; Diao, E.; Shen, T.; Qiang, Q. Acold-induced phytosulfokine peptide is related to the improvement of loquat fruit chilling tolerance. Food Chem. 2017, 232, 434-442. [CrossRef]

22. Eyéghé-Bickong, H.A.; Alexandersson, E.O.; Gouws, L.M.; Young, P.R.; Vivier, M.A. Optimization of an HPLC method for the simultaneous quantification of the major sugars and organic acids in grapevine berries. J. Chromatogr. 2012, 885, 43-49.

23. Huang, H.; Jing, G.; Wang, H.; Duan, X.; Qu, H.; Jiang, Y. The combined effects of phenylurea and gibberellins on quality maintenance and shelf life extension of banana fruit during storage. Sci. Hortic. 2014, 167, 36-42. [CrossRef]

24. Jiang, Y.; Joyce, D.C. ABA effects on ethylene production, PAL activity, anthocyanin and phenolic contents of strawberry fruit. Plant Growth Regul. 2003, 39, 171-174. [CrossRef]

25. Huang, H.; Jian, Q.J.; Jiang, Y.M.; Duan, X.W.; Qu, H.X. Enhanced chilling tolerance of banana fruit treated with malic acid prior to low-temperature storage. Postharvest Biol. Technol. 2016, 111, 209-213. [CrossRef]

26. Yang, A.; Zhang, Z.; Cao, A.; Hua, B. Studies of changes in sugar accumulation and lignin deposition during peach fruit endocarp development. Acta Hortic. Sin. 2009, 36, 1113-1119.

27. Liu, X.; Zhang, J.W.; Guo, L.X.; Liu, Y.Z.; Jin, L.F.; Hussain, S.B.; Du, W.; Zhao, D.; Peng, S.A. Transcriptome changes associated with boron deficiency in leaves of two citrus scion-rootstock combinations. Front. Plant Sci. 2017, 8, 317. [CrossRef]

28. Verbančič, J.; Lunn, J.E.; Stitt, M.; Persson, S. Carbon supply and the regulation of cell wall synthesis. Mol. Plant 2018, 11, 75-94. [CrossRef]

29. Chen, X.; Alonso, A.P.; Shacharhill, Y. Dynamic metabolic flux analysis of plant cell wall synthesis. Metab. Eng. 2013, 18, 78-85. [CrossRef] 
30. Shumei, L.; Su, X.; Muhammad, A.; Sun, Y.; Li, G.; Cheng, X.; Lin, Y.; Cai, Y.; Jin, Q. Effects of different pollens on primary metabolism and lignin biosynthesis in pear. Int. J. Mol. Sci. 2018, 19, 2273.

31. Schäfer, J.; Wagner, S.; Trierweiler, B.; Bunzel, M. Characterization of cell wall components and their modifications during post-harvest storage of Asparagus officinalis L.: Storage-related changes in dietary fiber composition. J. Agric. Food Chem. 2016, 64, 478-486.

32. Song, L.; Chen, H.; Gao, H.; Fang, X.; Mu, H.; Yuan, Y.; Yang, Q.; Jiang, Y. Combined modified atmosphere packaging and low temperature storage delay lignification and improve the defense response of minimally processed water bamboo shoot. Chem. Cent. J. 2013, 7, 147. [CrossRef] [PubMed]

33. Ring, L.; Yeh, S.Y.; Hucherig, S.; Hoffmann, T.; Blanco-Portales, R.; Fouche, M.; Villatoro, C.; Denoyes, B.; Monfort, A.; Caballero, J.L.; et al. Metabolic interaction between anthocyanin and lignin biosynthesis is associated with peroxidase FaPRX27 in strawberry fruit. Plant Physiol. 2013, 163, 43-60. [CrossRef]

34. Yi, C.; Jiang, Y.M.; Shi, J.; Qu, H.X.; Duan, X.W.; Yang, B.; Prasad, N.K.; Liu, T. Effect of adenosine triphosphate on changes of fatty acids in harvested litchi fruit infected by Peronophythora litchii. Postharvest Biol. Technol. 2009, 54, 159-164. [CrossRef]

35. Chumyam, A.; Shank, L.; Uthaibutra, J.; Saengnil, K. Effects of chlorine dioxide on mitochondrial energy levels and redox status of 'Daw' longan pericarp during storage. Postharvest Biol. Technol. 2016, 116, 26-35. [CrossRef]

36. Zhou, Q.; Zhang, C.; Cheng, S.; Wei, B.; Liu, X.; Ji, S. Changes in energy metabolism accompanying pitting in blueberries stored at low temperature. Food Chem. 2014, 164, 493-501. [CrossRef]

37. Pan, Y.G.; Yuan, M.Q.; Zhang, W.M.; Zhang, Z.K. Effect of low temperatures on chilling injury in relation to energy status in papaya fruit during storage. Postharvest Biol. Technol. 2017, 125, 181-187. [CrossRef]

38. Lin, Y.; Lin, Y.; Lin, H.; Ritenour, M.A.; Shi, J.; Zhang, S.; Chen, Y. Hydrogen peroxide-induced pericarp browning of harvested longan fruit in association with energy metabolism. Food Chem. 2017, 225, 31-36. [CrossRef]

(C) 2019 by the authors. Licensee MDPI, Basel, Switzerland. This article is an open access article distributed under the terms and conditions of the Creative Commons Attribution (CC BY) license (http://creativecommons.org/licenses/by/4.0/). 